\title{
Tourist Big Data, Mining and Their Application Direction in Tourism
}

\author{
Han Liu \\ College of Economics and Management, China Three Gorges University, Yichang Hubei, 443002, \\ China
}

Keywords: Tourist big data, Mining, Tourism, Application direction

\begin{abstract}
With rapid development of economy and ever-changing science and technology in recent years, tourism gradually develops prosperously and leads the trend of era development. Meanwhile, the arrival of big data era is also one of hot topics that current media focus on. How to apply tourist big data in tourism has been one of research focuses in tourism. This paper mainly studies tourist big data, mining and their application direction in tourism. Firstly, this paper summarizes big dada and tourist data mining, analyzes the necessity of applying tourist big data and mining in tourism and specific applications, and finally discussed the application direction in tourism.
\end{abstract}

\section{Introduction}

In the $21^{\text {st }}$ century, modern information technology becomes increasingly mature and internet popularizes. People's ability to produce data is enhanced. Hence, modern era gradually develops to big data direction. The explosive data plays certain role for network development. For tourism, how to grasp the correct direction in the development of big data era is always one of the focuses in tourism. Therefore, research and analysis of tourist big data, mining and their application in tourism have certain economic value and practical significance.

\section{Relevant overview of big data}

\section{Definition of big data}

Big data have difference definitions from diverse perspectives. Generally speaking, big data mainly refer to a data resource with relatively large capacity. Since big data have huge scale of data, it is difficult to rationally manage and gain big data with relevant software. For the essence, big data often own data resource and complex structure, but there are also many types of data sets.

\section{Features of big data}

Big data not only own huge data size and diversified data types, but also have low density and large value. Big processing is fast. In the formation process of big data, the data types upgrade gradually and the data size becomes bigger and bigger. As internet popularizes, popularize and the unit data pay more attention to basic structure of data in the evolution and formation process. Meanwhile, current network data have certain media data and log data, and the types are relatively numerous, without certain rules. Current big data not merely own low density, but also have large economic value. But, relatively large potential value often exists in data collection and processing process. Current big data have fast information processing speed. Thus, overall analysis and processing of mass data can be done, and the information and product service with huge value can be gained. The achievement of this process makes current big data own relatively profound insight.

\section{Tourist data mining}

\section{Definition of data mining}

From technical perspective, data mining refers to discover of data knowledge in a sense. The process of extracting mass data, noisy data and fuzzy data is actually the process of extracting the information with potential value. Data mining often needs relevant decision support to achieve automatic analysis of mass data, rationally conclude data, mine potential mode and offer necessary decision support for data collection. 
From commercial perspective, data mining is a relatively new commercial information processing technique. For instance, during processing tourism-related information, mass information is extracted, transformed, differentiated and modeled with the help of an information technology. In this process, decision information of information knowledge in tourism is extracted to fundamentally achieve spontaneous tourism business mode.

In one word, data mining as a comprehensive information processing technology involves techniques in multiple subjects. It not merely includes database technology, statistics knowledge and neural network, but also involves data visualization and information retrieval functions. It aims to achieve comprehensive data processing and mining. In tourist data mining, the data from multiple perspectives are gathered, and the management between information decision control and information is realized. Then, necessary decision support is provided for information query.

\section{Tourist data mining technology}

Data mining technology not merely includes information correlation analysis, information sequence pattern analysis, information sorting and clustering, but also involves detection of abnormal information. Tourist data mining mainly adopts correlation analysis, searches tourism-relates information in real time and adopts the pattern which appears most frequently. Tourist data similarity is analyzed through clustering and sorting, and the similar information is saved to offer necessary support for relevant decision makers.

\section{Necessity of applying tourist big data mining in tourism}

With rapid development of economy and progress of science and technology, modern big data are applied more and more extensively. Tourism also develops fast in China. The application of big data in tourism receives more and more attention so that relevant administrative departments in tourism gradually focus on actual application of big data and current research status.

As tourism develops at full speed, accurate design of tourism website requires application of big data technology to offer necessary help for tourists and recommend the optimal tourist attractions. Nowadays, the data of tourism websites are as many as 500 million of pages. The web pages of tourism websites not just include Hopper, but also cover tourism website and hotel search engines. Relevant information is recorded, and platform sharing design is done to enhance the relevance between tourists and the persons in charge of tourism. These fundamentally guarantee all-round and fast development of tourism.

With the development of information diversification based on big data, tourists just need to click the sightseeing district via websites, and relevant information will pop up automatically. Meanwhile, the products contain mass information in actual selection process, and tourists need to choose and judge them by themselves.

Besides, the application of tourist big data and mining in tourism is under the help of Baidu. Users can search data information via Baidu. The supply of tourist data not just guarantees good marketing development of tourism enterprises, but also plays an active role in monitoring tourism team and the number of tourists in a scenic spot.

All in all, the extensive application of tourist big data and mining in tourism not only facilitates rapid development of tourism enterprises, but offers certain convenience for people to scientifically gather and master tourism information. As well, it can not just accurately predict the trend of tourist flow, but directly master tourists' preference and greatly promotes improvement of public service in modern tourism. Thus, it is necessary to apply tourist big data and mining in tourism.

\section{Application of tourist big data and mining in tourism}

The application of tourist big data and mining in tourism not merely achieves hidden information mining, but provides important value information for modern tourism development. The application process is as follows: 


\section{To mine valuable tourism information}

In the process of mining valuable tourism information, big data analyze tourists' click rate for click rate and users' common browsing behaviors so as to grasp and gather travelling destinations tourists are interested in. In combination of the information mined by big data, tourism management departments should carry out optimal design of tourism information website and make sure website design is consistent with tourists' actual demand and make sure existing tourism services are more superior and comprehensive.

\section{To mine potential tourists}

In the process of mining potential tourists, comprehensive analysis and summary of tourist-related knowledge through data clustering analysis and according to tourists' access records. Meanwhile, the preference of potential tourists can be gathered and the tourism information tourists are most interested in can be recommended.

\section{To optimize tourist route}

During the application of tourist big data and mining in tourism, the tourist route with market potential can be gained through mining and analyzing tourists' access to tourism routes and destinations. Then, relevant tourist routes can be rationally planned. Dynamic processing of tourism website structure should be conducted, and website stickiness should increase effectively so as to improve website page view.

\section{To recommend tourist items and destinations}

Data mining can recommend tourist items and destinations. Through creating the tourism database covering all destinations and analyzing tourist' behaviors and interests with data mining tool, different types of tourism service schemes can form. According to tourists' actual tourism preference, the optimal tourist item and destination can be recommended for tourists to improve tourists' satisfaction.

In general, tourism is as an economic, complex and huge social activity. During comprehensive application of big data and mining, effective management of tourism is fundamentally achieved. The application of big data and mining not just facilitates scientific development and modernization construction of tourism, but offer high-quality service for all-round development of tourism. During the application of big data and mining in tourism, it is required to formulate national level tourists big data development strategy, make sure tourism management departments at all levels construct intelligent tourism platform, gather and master tourists' preference and ensure instantaneity and effectiveness of tourism information. At the same time, during the application of big data and mining in tourism, it is also required to analyze and mine mass information, enhance information management of tourism enterprises, overall improve digitization degree, optimize internal management procedure, intensify collection of customer information, accumulate customers' data and publicize valuable tourism information.

\section{Conclusion}

With rapid development of economy, tourist big data and mining technology also develop prosperously. The competition of tourism market becomes increasingly fierce. To better ensure better market development prospect, modern tourism enterprises should do information processing of tourist big data well, mine effective information, acquire valuable information, strive for more market development opportunities, rationally allocate tourism resources, continuously seek potential customers, offer individualized tourism services according to requirements of potential customers and overall drive rapid development of tourism.

\section{References}

[1] Peng Yafa, Xie Xiaolan, Study on Improving Core Competitiveness of Tourism in Jinhua with Data Mining. Computer Development \& Applications, 2013,03:7-10. 
[2] Guo Xin, Research of Tourist Big Data and Mining. Computer Knowledge and Technology, 2013,14:3215-3216.

[3] Luo Chengkui, Application of Big Data Technology in Intelligent Tourism. Tourism Overview (II), 2013,08:59-60.

[4] Deng Bing, Study on Bike Tour in Beijing Based on Big Dta Mining. Journal of Highway and Transportation Research and Development (Applied Technology Edition), 2014,07:299-302.

[5] Wu Yingying, Network Marketing Innovation of Tourism Enterprises under Big Data Background - Based on AISAS Consumer Behavior Analysis. China Business \& Trade, 2013,35:107-108.

[6] Luo Jianhua, Chen Jianke, Study on Data Mining Application Based on Tourism E-business. E-business, 2011,08:28+32. 